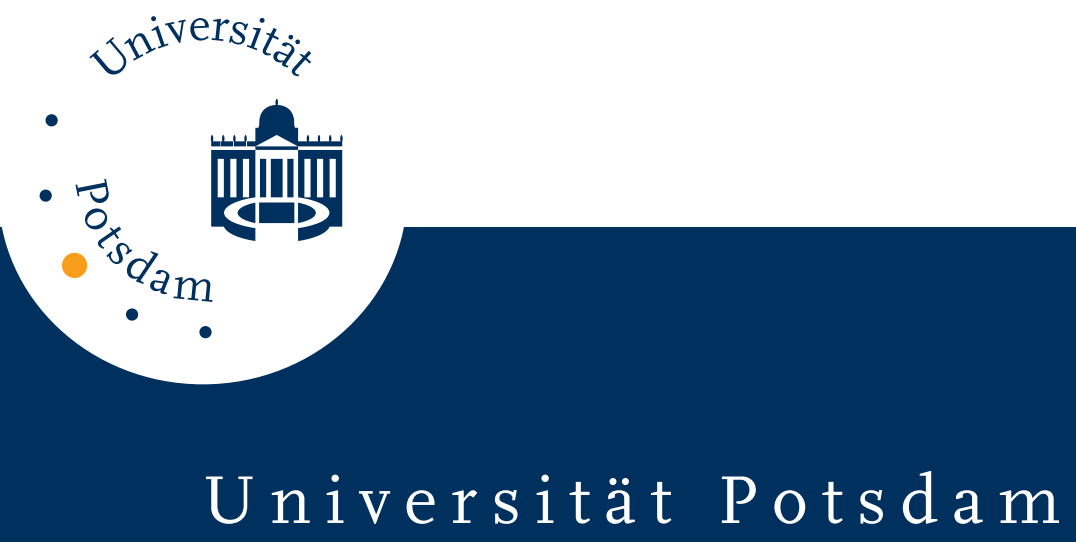

Ulrich Schiefele

\title{
The influence of topic interest, prior knowledge, and cognitive capabilities on text comprehension
}

first published in:

Learning environments / J. M. Pieter; K. Breuer; P. R. J. Simons (Eds.). Berlin : Springer, 1990. - S.323-338

Postprint published at the Institutional Repository of Potsdam University: In: Postprints der Universität Potsdam

Humanwissenschaftliche Reihe ; 47

http://opus.kobv.de/ubp/volltexte/2009/3347/

http://nbn-resolving.de/urn:nbn:de:kobv:517-opus-33472

Postprints der Universität Potsdam

Humanwissenschaftliche Reihe ; 47 


\title{
The Influence of Topic Interest, Prior Knowledge, and Cognitive Capabilities on Text Comprehension ${ }^{1}$
}

\author{
U. Schiefele \\ University of the Bundeswehr Munich, \\ Federal Republic of Germany
}

\begin{abstract}
The present study investigated the influence of topic interest on the comprehension of texts. The primary goals of the study were as follows: (1) to formulate a new definition of the concept "topic interest", (2) to control for cognitive capabilities (intelligence, short-term memory) and prior knowledge, and (3) to assess different levels of comprehension. A total of 53 male students, majoring in computer science, took part in the study. Subjects were presented with a text on "Psychology of Emotion". Prior to reading the text, they were asked to indicate their level of interest in the topic. After reading the text, subjects were given a test of comprehension involving open-ended questions. The questions were designed to represent different levels of comprehension. The results show that the effect of topic interest on text comprehension is especially pronounced when a deeper level of understanding is required. Surprisingly, prior knowledge had no effect on the level of comprehension. Verbal intelligence, on the other hand, showed a clear effect on comprehension, especially in answering questions of simple knowledge. The effects of interest and verbal intelligence could be shown to be independent of one another.
\end{abstract}

\section{INTRODUCTION}

The psychology of text comprehension is currently one of the most important areas in cognitive psychology. However, studies of learning involving texts are also extremely important from an educational point of view, since so much of school and university learning relies on texts. The research conducted up to now concerning the comprehension process and the conditions that influence it (e.g., Britton \& Black, 1985; Mandl, Ballstädt,

${ }^{1}$ The author wishes to thank Andreas Krapp, Beate Minsel, and Adolf Winteler for collecting the data. Special thanks are due to Steve Adams who translated the original manuscript.

In: Pieters, J. M., Breuer, K. \& Simons, P. R. J. (Eds.), Learning Environments. Berlin: Springer 1990. 
Schnotz, \& Tergan, 1980; Mandl \& Schnotz, 1987) has focused almost exclusively on structural characteristics of the text (e.g., coherence of the text, density of propositions), on cognitive characteristics of the reader (e.g., memory capacity, reading strategy, prior knowledge) and on task demands or goals (e.g., reading to understand or to summarise a text). Emotional and motivational factors, on the other hand, have been largely ignored. One exception are recent studies focusing on the effect of interest on text comprehension (Schiefele, 1988b).

Two different research approaches can be discerned here. The first approach treats interest as a dispositional, or trait-like variable and investigates the influence of topic interests on the retention and comprehension of texts (e.g., Asher, 1980; Baldwin, Peleg-Bruckner, \& McClintock, 1985). The second approach is concerned with the interestingness of texts or sentences (e.g., Anderson, Shirey, Wilson, \& Fielding, 1987; Hidi \& Baird, 1986). The study to be reported here adopts the first of these two approaches.

The majority of previous studies found a positive correlation between topic interest and quantitative measures of recall (cf. Schiefele, 1988b). These studies, however, contain a number of significant flaws:

(1) Lack of a well elaborated definition or theory of interest: most studies include no theoretical discussion of the concept of interest. Many authors rely instead on the everyday meaning of the term.

(2) Problematic measurement of interest: closely related to the first point is the inadequate operationalisation of individual interests. Usually, the subject is simply asked to estimate his or her level of interest in one or more topics by means of a single rating scale.

(3) Vagueness concerning the degree of independence of the interest effect from prior knowledge and cognitive capabilities: the few studies that addressed the interaction between interest and prior knowledge (Bald-win et al, 1985; Entin \& Klare, 1985; Hare \& Devine, 1983; Osako \& Anders, 1983; Weber, 1980) came to conflicting results. Baldwin et al., Weber, and Entin \& Klare could show that both interest and prior knowledge have a significant influence on comprehension, and that the two factors function independently of one another. Hare \& Devine, on the other hand, could confirm a significant influence only for prior knowledge. Osako \& Anders found weak effects for both prior knowledge and topic interest.

There are two possible explanations for these results. In the study performed by Hare \& Devine, the subjects obviously exhibited such high levels of prior knowledge that any differences in level of interest became largely irrelevant. In the study carried out by Osako \& Anders, the subjects knew 
to expect a test of comprehension following the reading phase. Assumably, this led to a high motivation to learn from the text that was independent of the level of topic interest.

Studies investigating the independence of interest and cognitive capability have involved almost exclusively school-age subjects, and have centred around reading ability (Osako \& Anders, 1983; Stevens, 1979; Walker, Noland, \& Greenshields, 1979; Weber, 1980). In those studies it could be shown that reading ability always exhibited a significant influence on text comprehension, and that this influence was independent of interest. Factors of intelligence and memory, however, were considered as control variables in only a very few studies.

(4) Neglect of qualitative and structural indicators of text comprehension: with few exceptions, most studies have used as the measure of comprehension a single quantitative indicator that, generally, was assessed by means of a multiple-choice test. This type of indicator gives no clear-cut information about the structural characteristics of the acquired knowledge, and allows no differentiation between various levels of comprehension.

The present study represents a first attempt to overcome the deficits outlined above. First of all, the question of a definition of topic interest must be addressed (see also Schiefele, in press).

Clearly, interest has to be recognised as being a domain-specific or topicspecific motivational characteristic of personality. Drawing on both older as well as newer theories of interest (cf. Prenzel, 1988; Schiefele \& Winteler, 1988) two components of interest can be distinguished: an emotional component and a value-based component. Recently developed concepts in the field of motivation theory can serve to define these components more precisely. Of special relevance is the taxonomy of motivational personality characteristics developed by Pekrun (1988). According to this taxonomy, motivational characteristics of personality include, among other things, declarative cognitive representations, which contain expectations, goals, and valences. With this in mind, the emotional and the value-based component can be reinterpreted as different types of valences. The emotional component consists of feeling-related valences, and the value-based component consists of value-related valences. The term "feeling-related valences" is used when a topic or object is related to feelings which either precede, accompany, or follow upon involvement with that topic or object. The term "value-related valences" is used when personal significance is assigned to an object or topic. It would therefore seem reasonable to define interest as being composed of both feeling-related valences (relating a topic with par- 
ticular feelings) and value-related valences (attributing personal significance to a topic).

In addition to the two components mentioned above, a third important aspect of the interest concept is its intrinsic character (cf. Prenzel, 1988). In the context of text learning, this means that involvement with a certain topic should not be instrumental for the achievement of goals that are external to that topic (e.g., passing an exam) or for receiving any positive rewards. The emotional and value-related components of interest, therefore, can be more precisely described as intrinsic feeling-related and valuerelated valences. Consequently, any attempt to measure interest must ensure that the valences under consideration relate directly to the topic and not to other, external goals, events, or topics. In addition, one can attempt to clarify the intrinsic character of interest in a certain topic by means of direct questions.

The second primary goal of the present study was to examine the independence of possible interest effects from cognitive control variables. The following factors were included: prior knowledge, verbal and general intelligence, and short-term memory capacity.

In order to determine possible effects of the independent variables on different levels of comprehension, the comprehension test included questions based on simple details, questions involving more complex facts, and questions requiring a deep level of understanding.

The following hypotheses were formulated: (1) interest exerts more influence when dealing with complex questions of knowledge and questions requiring deeper understanding; (2) intelligence and prior knowledge have equally strong effects on all indicators; (3) the effect of interest on comprehension is independent of factors of intelligence and prior knowledge.

\section{METHOD}

\section{Subjects}

A total of 53 male, first-semester students at the University of the Bundeswehr Munich took part in the study. All participants were majoring in computer science. On the basis of a questionnaire measuring topic interest, the sample was divided (by means of a median split) into a high interest group $(n=26)$ and a low interest group $(n=27)$, which were then compared with one another. 


\section{Measures}

Control variables

During the pretest phase (ca. 2 to 4 weeks prior to study begin) the following variables were assessed for each subject: prior knowledge, shortterm memory (STM) capacity, verbal intelligence, and general intelligence. Prior knowledge was assessed by means of an association test using the stimulus term "emotion", and by five open-ended questions that had to do with basic aspects of the text. The other variables were measured using five subtests of the WILDE-Intelligence-Test (Jäger \& Althoff, 1983). Of these, one subtest served to determine STM capacity, two subtests related to verbal intelligence, and two subtests had to do with reasoning and word fluency. The sum of the five subtests can be regarded as an estimate of total intelligence.

Topic interest

In the experimental phase, the subjects were first given a short abstract of the text. The measurement of topic interest was performed immediately afterwards. It had two parts. In the first part the subjects were asked to indicate how they expected to feel while reading the actual text (emotional component of interest). Six scales were used for this estimation. Feelings of involvement and stimulation ("bored", "engaged", "interested", "stimulated", "indifferent", "involved") were considered typical of interest. In the second part, the subjects were asked to rate the topic's personal meaning to them (value component of interest). Four scales were employed here ("useful", "unimportant", "meaningful", "worthless"). Responses to all interest items were based upon four-point scales. For each subject, the average value of each component was determined. Values for both components of interest were summed up to yield total interest values. For the feeling-related subscale, a reliability co-efficient of $\alpha=.91$ (internal consistency) was determined. For the value-related subscale, a reliability measure of $\alpha=.89$ was found. 
Dependent variables ${ }^{2}$

After reading the text, the subjects were given the test of comprehension and several rating scales to evaluate the text. The comprehension test contained 12 open-ended questions. In accordance with Ballstädt \& Mandl (1987), three types of questions were distinguished: simple questions of knowledge (SQK), complex questions of knowledge (CQK), and questions of deeper comprehension (QDC). Of the 12 questions, six belong to the first category, three belong to the second category, and three belong to the third category. The simple questions of knowledge refer to concrete details (e.g., individual facts, definitions) explicitly contained within the text. The complex questions of knowledge also pertain to knowledge explicitly contained in the text, but involve more extensive passages. The questions of deeper comprehension, on the other hand, require that the text information be recombined, that different parts of the text be compared with one another, or that text-based knowledge be applied in a new situation.

The analysis of the comprehension test was carried out by two student raters. The first step involved preparing a key with correct answers to all questions and establishing the best possible score. In the second step, all answers to each question were scanned, and necessary changes or additions to the key were made. This step in the analysis was conducted by the first rater, whose work was checked by the second rater. Both raters were then asked to independently evaluate, on the basis of the answer key, all of the answers given by the subjects. It was not possible for the raters to determine whether a subject belonged to the high or low interest group. The student evaluators disagreed on $10.3 \%$ of the total of $(53 \times 12=) 636$ answers. In those cases a consensus was worked out. Because some questions were worth more points than others, individual point scores were converted into $z$-scores. In order to arrive at only positive values, all $z$-scores were increased by 1 .

\section{Material}

Two criteria were used in selecting the topic. First of all, the subjects (computer science students) should have only limited prior knowledge about the topic. This was intended to prevent any confounding of the factors of interest and prior knowledge. Second, the extent of interest in

${ }^{2}$ Before the test of comprehension, the subjects were given several scales designed to measure cognitive and motivational process variables (activation, flow experience, elaborations, learning strategies). The corresponding results have been reported elsewhere (Schiefele, in press). 
the topic should display a large variance. The first criterion was fulfilled by selecting a topic that has nothing to do with the subjects' major. The second criterion was verified in a pilot study. The topic finally selected was "Psychology of Emotion". The article was five pages in length and had two parts. Following a short introduction, the first part was entitled "Emotion as a Subjective Experience". The second part was entitled "Emotion as a Physiological Reaction".

\section{Procedure}

All tests and questionnaires were completed by students in three introductory seminars. The subjects always participated in groups with ca. 18 members. The seminars' regular teachers served as the experimenters. Two to four weeks after pretesting for the control variables, the actual study was conducted. At the beginning of the session the subjects were told that the study had to do with the quality of textbooks, and that they were being asked to evaluate a text. The instructions were given in such a way that the students did not expect a test of comprehension. This was done in order to ensure that they did not adopt a task orientation, which would cover up any interest effect (cf. Osako \& Anders, 1983). The subjects were then told the topic of the text and were given a short summary of the text to read. Following this, they were asked to indicate their degree of interest in the topic, and were given 15 minutes to read the text. After completing the reading phase the students had to evaluate the text and to answer the 12 questions of comprehension.

\section{RESULTS}

The data analysis focuses on the differences between subjects with high and low levels of interest. First, the central question of the study, namely the appearance of comprehension differences between high and low interest subjects, will be addressed. Following that, the question whether the interest effect is independent of the control factors prior knowledge, intelligence, and STM capacity will be investigated.

\section{Topic interest and comprehension}

The data analysis was conducted using a 2 × 3 MANOVA, with interest as a between-subjects factor and level of comprehension as a within-subjects factor. A significant main effect for interest could be obtained, $F(1,51)=$ 10.03, $\mathrm{MSe}=0.55, \mathrm{p}<.005$ (see Table 1$)$. 
Table 1: Differences in Comprehension as a Function of Topic Interest.

$\begin{array}{ll}\text { Low } & \text { Topic interest } \\ (\mathrm{n}=27) & \text { High } \\ & (\mathrm{n}=26)\end{array}$

Comprehension test

M SD

M SD

SQK

0.88

.34

1.13

1.18

QDC

0.83

.59

Total

$0.74 \quad .72$

$0.83 \quad .38$

$1.27 \quad .51$

$1.17 \quad .44$

Notes: $\mathrm{SQK}=$ Simple questions of knowledge, $\mathrm{CQK}=$ Complex questions of knowledge, $\mathrm{QDC}=$ Questions of comprehension.

Additional comparisons of means using the Tukey-Test showed that the significant main effect for interest is primarily attributable to a difference between the two interest groups in answering questions requiring a deep level of comprehension, $\mathrm{KD}=0.51, \mathrm{p}<.001$. The differences for both the simple, $\mathrm{KD}=0.29, n s$, and complex questions of knowledge, $\mathrm{KD}=0.29, \mathrm{p}<$ .05 , are noticeably smaller. Overall, the pattern of results clearly confirms the hypothesis that interest exhibits more influence as the complexity of the indicators of comprehension increases.

These results, which rely on a content analysis of open-ended questions, were compared to the more objective measure of the length of each of the subjects' answers. To this end, the words used in answering each of the questions were counted and the number recorded. The results involving all three types of questions show that high interest subjects gave longer answers (cf. Table 2). However, no significant main effect for interest was revealed (MANOVA). The reported differences in comprehension cannot, therefore, be attributed to the fact that highly interested subjects simply gave longer answers. Instead, this difference is attributable to a different level of correctness of the answers given. 
Table 2: Length of Answer as a Function of Topic Interest.

\begin{tabular}{|c|c|c|c|c|}
\hline \multirow[b]{3}{*}{ Comprehension test } & \multicolumn{3}{|c|}{ Topic interest } & \\
\hline & \multicolumn{2}{|c|}{$\begin{array}{l}\text { Low } \\
(n=27)\end{array}$} & \multicolumn{2}{|c|}{$\begin{array}{l}\text { High } \\
(n=26)\end{array}$} \\
\hline & M & SD & $\mathbf{M}$ & SD \\
\hline SQK & 13.62 & 4.53 & 15.73 & 3.85 \\
\hline CQK & 22.73 & 9.69 & 25.99 & 8.90 \\
\hline QDC & 24.51 & 10.74 & 26.86 & 10.16 \\
\hline Total & 18.62 & 6.26 & 21.08 & 5.02 \\
\hline
\end{tabular}

Notes: The values listed represent the average number of words per question.

The influence of prior knowledge, intelligence, and short-term memory capacity

The finding that comprehension differs between high and low interest subjects coincides with a series of study results (cf. Schiefele, 1988b). However, the question whether the interest effect is independent of such important factors as prior knowledge, intelligence, and STM capacity remains unanswered. The following analysis should shed some light on this problem. While examining the results, it should be noted that not all subjects included in the sample took part in the data collection for the control variables. This is due to the fact that participation in the seminars in which the study was conducted fluctuated widely. A total of 42 subjects was used to determine prior knowledge ${ }^{3}$, and 30 subjects were available for the remaining variables. The first step in the analysis consisted of comparing the means of the control variables for high and low interest subjects with one another (Table 3). No significant differences could be determined. The mean values for general intelligence, verbal intelligence, STM capacity, and prior knowledge were all almost equal for high and low interest subjects. Only the analysis of the association test shows that subjects with a high level of interest tend to make more associations than their counterparts.

3 The test of prior knowledge, which consisted of open-ended questions, was analysed in similar fashion to the test of comprehension. 
Table 3: Values of Control Variables as a Function of Topic Interest.

\begin{tabular}{|c|c|c|c|}
\hline \multirow[b]{3}{*}{ Control variables } & \multicolumn{2}{|c|}{ Topic interest } & \multirow[b]{3}{*}{ SD } \\
\hline & Low & High & \\
\hline & SD & M & \\
\hline Intelligence factors & $(\mathrm{n}=15)$ & \multicolumn{2}{|c|}{$(\mathrm{n}=15)$} \\
\hline Short-term memory ${ }^{\mathbf{a}}$ & 108.607 .64 & 110.33 & 8.70 \\
\hline Verbal intelligence $^{\mathbf{a}}$ & 113.639 .02 & 113.20 & 10.12 \\
\hline General intelligence $^{a}$ & $111.45 \quad 5.52$ & 111.44 & 6.52 \\
\hline Prior knowledge I & $(n=21)$ & \multicolumn{2}{|c|}{$(\mathrm{n}=21)$} \\
\hline Open-ended questions ${ }^{\mathbf{b}}$ & $-.011 \quad .56$ & .011 & .58 \\
\hline Prior knowledge II & $(n=20)$ & \multicolumn{2}{|c|}{$(n=21)$} \\
\hline Number of associations $\mathbf{c}$ & $14.90 \quad 4.45$ & 16.71 & 6.03 \\
\hline
\end{tabular}

Notes: a Standard values, range: $70-130 ;{ }^{\mathbf{b}} z$-scores; ${ }^{\mathbf{c}}$ one subject in the low interest group did not fill out the association test.

On the basis of the control variable analysis, one must conclude that the differences in comprehension observed between the high and low interest groups are not attributable to the factors of intelligence, STM and prior knowledge. This result is of special significance, because previous studies have found these factors to be especially important in the learning of text material (Baldwin et al., 1985; Perfetti, 1983). For this reason it seems appropriate to investigate the relationship between these variables and comprehension. First of all, it can be seen that interest exhibits no particular correlation to either of the two tests of prior knowledge (association test: $\mathrm{r}=.14, \mathrm{n}=41, n s$; open-ended questions: $\mathrm{r}=-.03, \mathrm{n}=42, n s)$, to general intelligence $(r=.06, n=30, n s)$, to verbal intelligence $(r=.04, n$ $=30, n s)$, or to STM capacity $(r=.14, n=30, n s)$. The two tests of prior knowledge exhibited a correlation of $.32(\mathrm{n}=.41, \mathrm{p}<.05$, one-tailed test). Two questions now become of special importance: first, whether or not prior knowledge, STM capacity and intelligence significantly influence comprehension, and, secondly, whether or not any such effect is independent of the observed interest effect. First it should be noted that, contrary 
to expectations, prior knowledge exhibited no correlation to the measures of comprehension. This is equally true for both measures of prior knowledge. The corresponding correlation coefficients lie between -.14 and .14 (all $n s$ ).

Table 4 shows the results of the correlation analysis of the relationships between verbal intelligence, general intelligence, STM capacity and comprehension.

Table 4: Product Moment Correlations between Intelligence Factors, STM Capacity and Text Comprehension.

SQK $\quad$ CQK QDC Total

Short-term memory

Verbal intelligence

$\begin{array}{lrrr}.20 & -.10 & -.36^{*} & -.11 \\ .39^{*} & .27 & .10 & .34^{*} \\ .43^{* *} & .05 & -.19 & .14\end{array}$

General intelligence

Notes: $\mathrm{n}=30 ;{ }^{*} \mathrm{p}<.05,{ }^{* *} \mathrm{p}<.01$ (one-tailed tests).

The results are very informative. The indicators of verbal and general intelligence are of significance only in the case of simple questions of knowledge. If one looks at the total values, it can be seen that only the correlation between verbal intelligence and comprehension is statistically significant. Contrary to expectations, STM capacity is not related positively to comprehension. This result requires further examination.

In order to examine whether interest and intelligence show independent effects in the sub-sample analysed here, it is sufficient to consider the factor of verbal intelligence. In order to determine whether the correlation between interest and comprehension is affected by controlling for verbal intelligence, partial correlation co-efficients were computed. The first line of Table 5 depicts the zero-order correlations between interest and comprehension. For the purposes of comparison, the corresponding correlations for the entire sample are shown in line two. Values for the partial correlation co-efficients are given in the third line. 
Table 5: Product Moment and Partial Correlations between Interest and Text Comprehension.

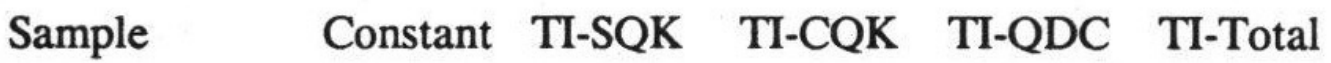

Total sample

(n = 53)

(n = 30)

$\quad .33^{* *}$

$.23^{*}$

$.44^{* * *}$

$.44^{* * *}$

Sub-sample

.26

.18

$.33^{*}$

$.35^{*}$

$(\mathrm{n}=30)$

Verbal in-

telligence .27

.18

$.33^{*}$

$.35^{*}$

Notes: ${ }^{*} \mathrm{p}<.05,{ }^{* *} \mathrm{p}<.01,{ }^{* * *} \mathrm{p}<.001$ (one-tailed tests). TI: Topic interest.

From Table 5 one can see that in the total sample interest exhibits significant correlations with all indicators of comprehension. Only the correlation with complex questions of knowledge was relatively small. A similar pattern of results could be discerned in the sub-sample, although the correlations between interest and the simple and complex questions of knowledge were not significant. The analysis of partial correlations shows that the correlations between interest and comprehension were not reduced by controlling for verbal intelligence. It therefore follows that the effects of interest and intelligence are independent of one another.

\section{DISCUSSION}

Topic interest has been shown in this study to be an important motivational condition of text comprehension. The effect on text comprehension, as indicated by responses to open-ended questions, was especially pronounced in the case of questions of deeper understanding. These questions required the subjects to compare and recombine certain aspects of the text and to transfer that information to new situations. Differences of less statistical significance could also be seen on the questions involving complex facts. These findings can be interpreted in one of three ways. One possibility would be that the comprehension of complex (or simple) facts represents a pre-requisite for deeper comprehension. It is conceivable that even minor "errors" made during the learning of important details could 
be magnified when the subject is called upon to answer questions that require more than simple memorisation of facts. If this were the case, then the differences in the comprehension of (simple or complex) details would be decisive. The second possibility postulates that a retrieval effect is involved - that the answering of complex questions of understanding is more strongly influenced by the subject's level of motivation. In other words, the subjects with low interest are equally capable of correctly answering a question of understanding, but are simply not motivated to go through the trouble to do so. The third possibility is that differences, in terms of the questions of deeper understanding, are attributable to different levels of processing while reading. That would mean that less interested subjects are equally capable of processing simple or complex facts (the differences observed were relatively small), but acquire no deeper understanding of the text content. On the basis of the data gathered in this study, it is difficult to justify choosing one of these three possibilities over the other two. Recent studies discredit at least the first of these hypotheses. Benware \& Deci (1984), for example, found that intrinsically motivated students, though clearly superior to less motivated students in terms of conceptual comprehension of a text, were no more capable of remembering individual details. Schiefele (1988a) and Schiefele, Winteler, \& Krapp (1988) found that students with low interest in their major were nevertheless able to produce as many subject-specific associations as their high interest colleagues. Analysis of the quality of those associations, however, revealed significant differences.

The present study has shown that prior knowledge, STM capacity and factors of intelligence are independent of level of interest. While this result was expected for the variables of intelligence and STM, the lack of correlation between prior knowledge and interest requires explanation. There would appear to be two alternative explanations. On the one hand, both tests of prior knowledge make clear that the level of professional understanding of the concept "emotion" was quite low". This was to be expected and is in line with the purpose of the study. In this sense, a small correlation between interest and prior knowledge is not particularly surprising. What is amazing is that existing differences in prior knowledge did not lead to a main effect that was statistically significant. This brings us to the

4 An additional content analysis of the associations clearly showed that both high and low interest subjects interpreted the concept "emotion" in an everyday sense. For both groups, the most frequent associations were "love", "hate", "happiness", "depression", "friendship", and "anger". 
second possible explanation, whereby the validity of the tests of prior knowledge must be called into question. In other words, it is possible that relevant bits of prior knowledge were in fact present, but could not be measured. It is, therefore, an important task of future studies to both improve the measurement of prior knowledge and to compare topics with one another where differing levels of prior knowledge can be expected.

The results of the present study, as well as the results of others (e.g., Baldwin et al., 1985; Osako \& Anders, 1983), seem to indicate that the obtained level of correlation between interest and text comprehension depends primarily on the extent of prior knowledge. In areas where an individual has no or only little prior knowledge (as was the case for the subjects involved in the present study), level of interest will presumably be relatively important. As an individual continues to work in a topic area, however, it is likely that level of interest and knowledge will converge, i.e., the greater the level of interest the more an individual will learn. This could be the reason why some studies found high correlations between interest and prior knowledge with regard to certain topics (e.g., Weber, 1980). Assuming an individual possesses extensive expertise in a topic area, any new learning in that area will undoubtedly be determined by what the individual already knows ${ }^{5}$. At this level, interest exerts only an indirect influence, i.e., interest could be responsible for achieving a high level of knowledge that will be expanded continuously. The validity of this premise could best be determined by means of a longitudinal study.

\section{REFERENCES}

Anderson, R.C., Shirey, L.L., Wilson, P.T., \& Fielding, L.G. (1987). Interestingness of children's reading material. In R.E. Snow \& M.J. Farr (Eds.), Aptitude, learning, and instruction. Vol. 3: Conative and affective process analyses (pp. 287-299). Hillsdale, NJ: Lawrence Erlbaum.

Asher, S.R. (1980). Topic interest and children's reading comprehension. In R.J. Spiro, B.C. Bruce, \& W.F. Brewer (Eds.), Theoretical issues in reading comprehension (pp. 525-534). Hillsdale, NJ: Lawrence Erlbaum.

Baldwin, R.S., Peleg-Bruckner, Z., \& McClintock, A.H. (1985). Effects of topic interest and prior knowledge on reading comprehension. Reading Research Quarterly, 20, 497-504.

5 Expertise in a field can be even more influential than cognitive capabilities (e.g., Schneider, Körkel, \& Weinert, in press). 
Ballstädt, S.-P., \& Mandl, H. (1987). Influencing the degree of reading comprehension. In E. van der Meer \& J. Hoffmann (Eds.), Knowledge aided information processing (pp. 119-139). Amsterdam: Elsevier.

Benware, C.A., \& Deci, E.L. (1984). Quality of learning with an active versus passive motivational set. American Educational Research Journal, 21, 755-765.

Britton, B.K., \& Black, J.B. (Eds.) (1985). Understanding expository text. Hillsdale, NJ: Lawrence Erlbaum.

Entin, E.B., \& Klare, G.R. (1985). Relationships of measures of interest, prior knowledge, and readability to comprehension of expository passages. Advances in Reading/Language Research, 3, 9-38.

Hare, V.C., \& Devine, D.A. (1983). Topical knowledge and topical interest predictors of listening comprehension. Journal of Educational Research, 76, 157-160.

Hidi, S., \& Baird, W. (1986). Interestingness - A neglected variable in discourse processing. Cognitive Science, 10, 179-194.

Jäger, A.O., \& Althoff, K. (1983). Der WILDE-Intelligenz-Test (WIT) [The WILDE intelligence test (WIT)]. Göttingen: Hogrefe.

Mandl, H., Ballstädt, S.-P., Schnotz, W., \& Tergan, S.-O. (1980). Lernen mit Texten [Learning with texts]. Zeitschrift für Entwicklungspsychologie und Pädagogische Psychologie, 12, 44-74.

Mandl, H., \& Schnotz, W. (1987). New directions in text comprehension. In E. De Corte, H. Lodewijks, R. Parmentier \& P. Span (Eds.), Learning and instruction (pp. 321-338). Oxford/Leuven: Pergamon Press/Leuven University Press.

Osako, G.N., \& Anders, P.L. (1983). The effect of reading interest on comprehension of expository materials with controls for prior knowledge. In J.A. Niles \& L.A. Harris (Eds.), Searches for meaning in reading/language arts processing instruction (pp. 56-60). Rochester, NY: National Reading Conference.

Pekrun, R. (1988). Emotion, Motivation und Persönlichkeit [Emotion, motivation and personality]. München/Weinheim: Psychologie Verlags Union.

Perfetti, C.A. (1983). Individual differences in verbal processes. In R.F. Dillon \& R.R. Schmeck (Eds.), Individual differences in cognition, Vol. 1 (pp. 65-104). New York: Academic Press.

Prenzel, M. (1988). Die Wirkungsweise von Interesse [The way interest works]. Opladen: Westdeutscher Verlag.

Schiefele, U. (1988a). Der Einfluß von Interesse auf Umfang, Inhalt und Struktur studienbezogenen Wissens [The influence of interest on size, content and structure of study-related knowledge]. Zeitschrift für Entwicklungspsychologie und Pädagogische Psychologie, 20, 356-370.

Schiefele, U. (1988b). Motivationale Bedingungen des Textverstehens [Motivational conditions of text comprehension]. Zeitschrift für Pädagogik, 34, 687-708.

Schiefele, U. (in press). Thematisches Interesse, Variablen des Leseprozesses und Textverstehen [Thematic interest, variables of the reading process and text comprehension]. Zeitschrift für Experimentelle und Angewandte Psychologie.

Schiefele, U., \& Winteler, A. (1988). Interesse - Lernen - Leistung. Eine Übersicht über theoretische Konzepte, Erfassungsmethoden und Ergebnisse der Forschung [Interest - learning - result. An overview of theoretical concepts, working concepts and research results]. Gelbe Reihe, Arbeiten zur Empirischen 
Pädagogik und Pädagogischen Psychologie, Nr. 14. München: Univer-sität der Bundeswehr, Institut für Erziehungswissenschaft und Pädagogische Psychologie.

Schiefele, U., Winteler, A., \& Krapp, A. (1988). Studieninteresse und fachbezogene Wissensstruktur [Study interest and profession-related knowledge structure]. Psychologie in Erziehung und Unterricht, 35, 106-118.

Schneider, W., Körkel, J., \& Weinert, F.E. (in press). Expert knowledge, general abilities, and text processing. In W. Schneider \& F.E. Weinert (Eds.), Interactions among aptitudes, strategies, and knowledge in cognitive performance. New York: Springer.

Stevens, K. (1979). The effect of topic interest on the reading comprehension of higher ability students. Journal of Educational Research, 73, 365-368.

Walker, S.M., Noland, R.G., \& Greenshields, C.M. (1979). The effect of high and low interest content on instructional levels in informal reading inventories. Reading Improvement, 16, 297-300.

Weber, C.K. (1980). Cognitive and affective influences on text comprehension. Dissertation Abstracts International, 40, 5802-A. 